\title{
Probiotic Supplements: Hope or Hype?
}

\begin{abstract}
Yuxuan Wang ${ }^{\dagger}$, Yinyin Jiang ${ }^{\dagger}$, Yuxin Deng, Chen Yi, Yangcan Wang, Mengnan Ding, Jie Liu, Xuanjing Jin, Lishan Shen, Yue He, Xinyun Wu, Xuefei Chen, Changyi Sun, Min Zheng, Ruijia Zhang, Hailv Ye, Huiting An and Aloysius Wong*
\end{abstract}

Department of Biology, College of Science and Technology, Wenzhou-Kean University, Wenzhou, China

Probiotic bacteria have been associated with various health benefits and included in overwhelming number of foods. Today, probiotic supplements are consumed with increasing regularity and record a rapidly growing economic value. With billions of heterogeneous populations of probiotics per serving, probiotic supplements contain the largest quantity of probiotics across all functional foods. They often carry antibioticresistant determinants that can be transferred to and accumulate in resident bacteria of the gastrointestinal tract and risk their acquisitions by opportunistic pathogens. While the health benefits of probiotics have been widely publicized, this health risk, however, is underrepresented in both scientific studies and public awareness. On the other hand, the human gut presents conditions that are unfavorable for bacteria, including probiotics. It remains uncertain if probiotics from supplements can tolerate acids and bile salts that may undermine their effectiveness in conferring health benefits. Here, we put into perspective the perceived health benefits and the long-term safety of consuming probiotic supplements, specifically bringing intolerance to acids and bile salts, and the long-standing issue of antibiotic-resistant gene transfer into sharp focus. We report that probiotics from supplements examined in this study have poor tolerance to acids and bile salts while also displaying resistance to multiple antibiotics. They could also adapt and gain resistance to streptomycin in vitro. In an environment where consuming supplements is considered a norm, our results and that of others will put in perspective the persisting concerns surrounding probiotic supplements so that the current hype does not overpower the hope.

\footnotetext{
Keywords: probiotics, antibiotic resistance, health/dietary supplements, horizontal gene transfer, adaptive evolution, Lactobacillus, lactic acid bacteria
}

\section{INTRODUCTION}

In the natural environments, antibiotics are found in much lower concentrations than that used in therapeutics. They are thought to serve as signals that enable the host to perform various physiological functions including intercellular communication, regulation of cellular metabolism, triggering intracellular transcriptional changes in response to stresses, and inhibiting the growth of competing bacteria populations (Haas and Défago, 2005; Yim et al., 2006, 2007; Fajardo and Martínez, 2008; Romero et al., 2011). Antibiotics act by inhibiting enzymes directly involved in cell wall and protein or nucleic acid metabolisms [see reviews by O'Connell (2001), Martinez et al. (2009), Kohanski et al. (2010), Du Toit (2018)]. Correspondingly, bacteria have intrinsic cellular mechanisms that shield them against the very same antibiotics that they produce [see reviews by Hawkey (1998), O'Connell (2001), 
Martinez et al. (2009), Stokes and Gillings (2011), Blair et al. (2014), Lin et al. (2015)] (Figure 1A). Genes that encode for resistance can be acquired through mobile elements such as plasmids and transposons, transformation or transduction via bacteriophages, or spontaneous mutations that repurpose existing efflux pumps or enzymes to recognize antibiotics (Woodford and Ellington, 2007; Bennett, 2008; Stokes and Gillings, 2011; Bielecki et al., 2012; Gutierrez et al., 2013; Balcazar, 2014; Colavecchio et al., 2017; Jiang et al., 2017; Figure 1A).

Consumption of probiotics in large amounts and high frequency in the form of health or dietary supplements can accelerate these natural ways of acquiring resistance. Probiotics are associated with increasing health benefits ranging from improving nutrient absorption and immune system (Perdigon et al., 2001; Kaur et al., 2002) to preventing cancer (Hirayama and Rafter, 2000) and cardiovascular-related diseases (Nagpal et al., 2012; Kechagia et al., 2013). As such, probiotics have been included in overwhelming number of foods such as yogurt, cheese, milk, and ice cream (Homayouni et al., 2012). In reflection of their popularity, current market survey has placed probiotic supplements as the driving force of the functional foods industry that is projected to reach 64 billion USD by 2023 (Zheng et al., 2017). Today, probiotic supplements represent the largest quantity of probiotic bacteria consumed by people across all food categories as they contain billions of often heterogeneous populations of probiotic bacteria per serving. Furthermore, commercial probiotic strains are deliberately engineered to carry resistant determinants during the manufacturing process for selection purpose. The resistant genes carried on mobile elements of probiotics can be transferred by horizontal gene transfer to resident gut bacteria (Broaders et al., 2013), which over time can accumulate resistant determinants that may in turn be transferred to opportunistic pathogens within the gastrointestinal tract (Figure 1B). This health risk has also been raised by others (Gueimonde et al., 2013; Penders et al., 2013; Rolain, 2013; Hu et al., 2014; Sharma et al., 2014; van Schaik, 2015; Wong et al., 2015; Imperial and Ibana, 2016; Duranti et al., 2017; Zheng et al., 2017; Lerner et al., 2019). Based on studies conducted in other probiotic foods, it is likely that probiotic supplements pose a similar if not an even higher risk of trafficking resistant determinants because of the significantly higher amounts of probiotics consumed. Unlike other categories of functional foods, very little is known about the long-term safety of consuming such high amounts of probiotic bacteria, as studies on this category of functional food are underrepresented.

On the other hand, probiotic bacteria must navigate an arduous journey beginning in the mouth to the stomach and throughout the gastrointestinal tract in order to effectively confer health benefits (Figure 1C). For instance, the $\mathrm{pH}$ can reach as low as 1.0 in the stomach, rising to 6.6 in the proximal small intestine and 7.5 in the ileum before falling sharply to 6.4 in the cecum, which is inhibitory to most bacteria, including probiotics (Evans et al., 1988). Bile salts have also been shown to inhibit the growth of probiotics (Liong and Shah, 2005; Succi et al., 2005; Kristoffersen et al., 2007; Sahadeva et al., 2011; Hassanzadazar et al., 2012). Unlike the health claims of probiotic supplements, their tolerance to acids and bile salts remains uncertain, and in cases where these properties are examined, the results were inconsistent, contradictory, strain dependent, transient, and limited to in vitro conditions (Liong and Shah, 2005; Kristoffersen et al., 2007; Sahadeva et al., 2011). Furthermore, probiotic strains are often studied in pure homogeneous cultures where absence of other probiotics and/or resident bacteria in the gut can skew the results to favor the interest of manufacturers. Additionally, a recent review has highlighted other concerns associated with probiotics such as inadequate or problematic research design, incomplete reporting, lack of transparency and regulations of probiotics, and underreported safety of probiotics consumption (Lerner et al., 2019). Therefore, probiotic supplements may not only be ineffective, they may also be counterproductive and even detrimental, considering the clinical risk and escalating reports of antibiotic resistance globally. Here, we put into perspective the perceived health benefits and the long-term safety of consuming probiotic supplements by bringing intolerance to acids and bile salts and the long-standing issue of antibiotic resistance into sharp focus.

\section{PROBIOTICS FROM HEALTH SUPPLEMENTS HAVE POOR TOLERANCE TO ACIDS AND BILE SALTS}

Here, we tested several representative probiotic supplements for their tolerance to acids and bile salts. The probiotic supplements contained predominantly Lactobacillus strains and were manufactured in China or Canada. The supplements were designated as $\mathrm{A}, \mathrm{B}, \mathrm{C}, \mathrm{D}, \mathrm{E}$, and $\mathrm{F}$, and their probiotic strains are listed in Supplementary Table 1. First, Lactobacillus strains from the capsules or tablets were recovered on de Man, Rogosa, and Sharpe (MRS) agar to determine if the probiotics are viable. We then enumerated the viable bacteria using the drop-plate method and compare that to the amounts on the labels. We recovered more than $90 \%$ of bacteria for products $\mathrm{A}, \mathrm{B}, \mathrm{C}$, and $\mathrm{E}$ at 99, 91, 94, and 98\%, respectively, whereas product D contained $128 \%$ enumerated amounts of bacteria. Thus, all products contained live bacteria with amounts comparable to that claimed by the manufacturers except for product $\mathrm{F}$, which recovered only $68 \%$ live bacteria (Figure $2 \mathrm{~A}$ ). Because product $\mathrm{F}$ is in liquid form, it may not preserve the probiotics, as well as others that were in solids or desiccated forms. All products except product $\mathrm{F}$ yielded viable bacteria counts exceeding $10^{6}$ colonyforming units per serving, which is the suggested probiotics amount deemed sufficient to confer health benefits (Shah, 2000).

Next, we checked if probiotics from these supplements can tolerate acids and bile salts by treating them to a $\mathrm{pH}$ range of 1.5 to 4.5 , with $\mathrm{pH} 7.4$ as the control. In this test, we dissolved the products in phosphate-buffered saline (PBS) adjusted to the respective $\mathrm{pHs}$ and with or without the presence of $0.3 \%$ (wt/vol) bile salts. The dissolved products were dropped onto MRS agar plates and incubated at $37^{\circ} \mathrm{C}$ for $24 \mathrm{~h}$. We took highresolution images and used ImageJ (Schneider et al., 2012) to measure pixel intensities of bacteria spots, which correlate with their amounts or densities. We found that probiotic bacteria from product $B$ grew poorly in acidic conditions, and they 
A

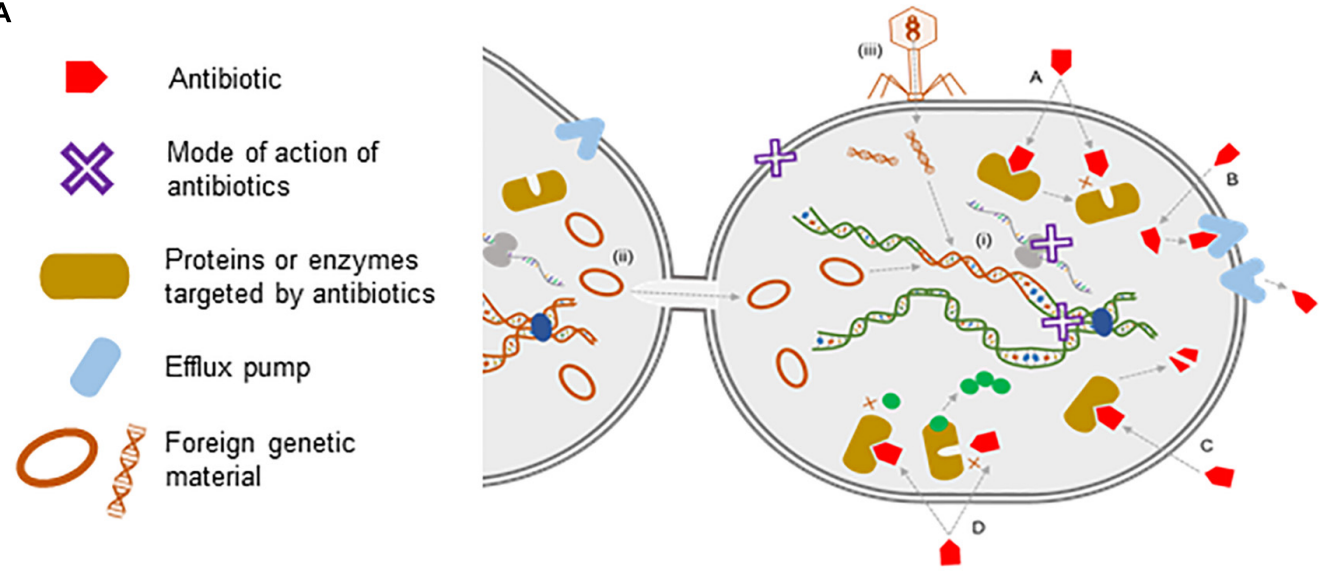

B

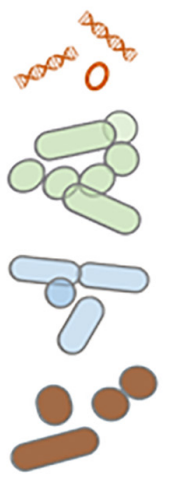

Resistant determinants

Host

microflora

Probiotic

bacteria

Pathogen

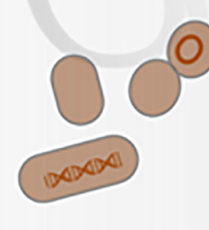

(0)

(v)

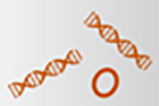

(i)

(ii)
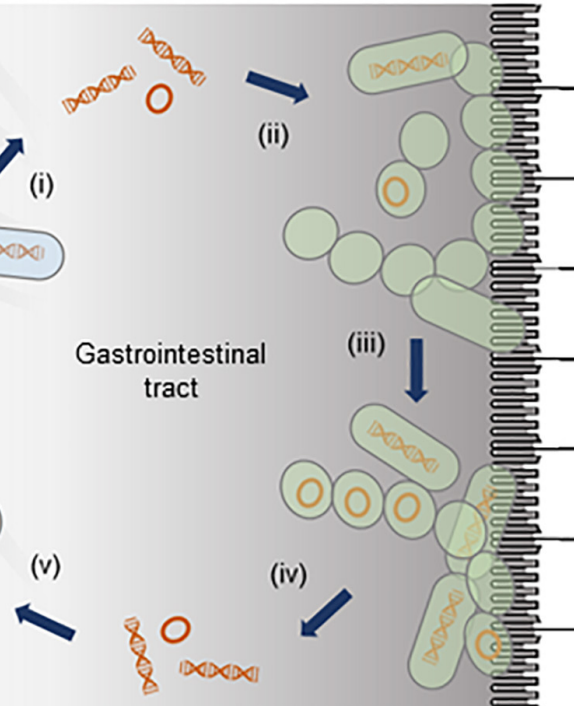

(iv)

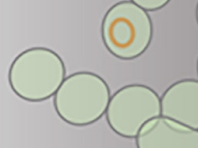

Gastrointestinal

(iii)
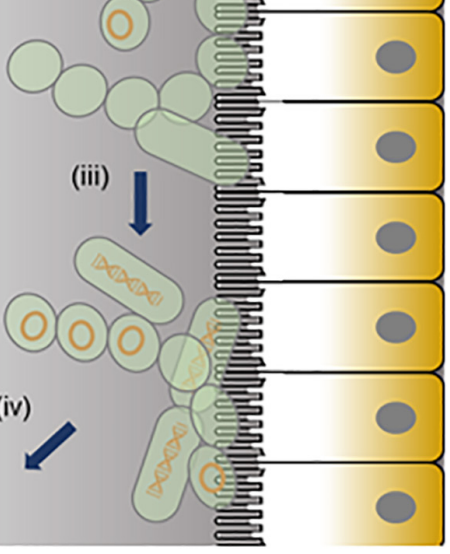

C

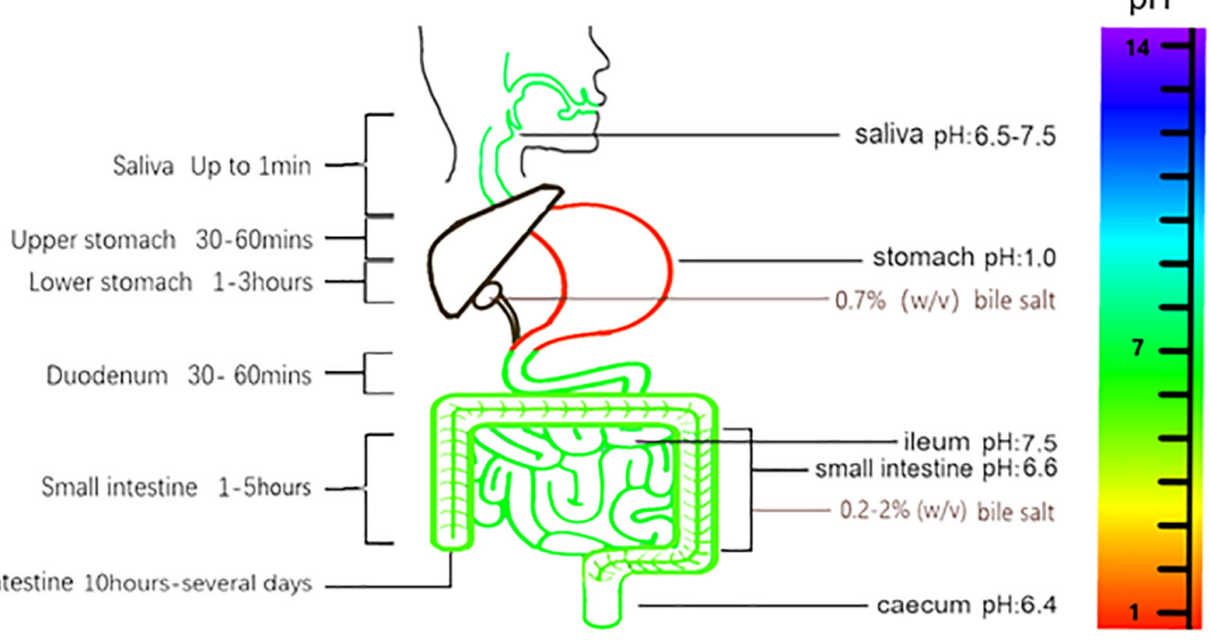

FIGURE 1 | Antibiotics and their resistance in the human gut. (A) An illustration of the mode of actions of antibiotics, the transmission of resistant determinants, and the biochemistry of antibiotic resistance. Antibiotics, either bacteriostatic or bactericidal, can exert their effects through the inhibition of enzymes involved in cell wall synthesis, the inhibition of protein translation at small or large ribosomal subunits, or the inhibition of nucleic acid metabolism in the bacterial cell as represented by a purple $\mathrm{X}$ in the diagram. Bacteria gain resistance to antibiotics through (i) mutations to the bacteria genome or by acquiring mobile elements via horizontal gene transfer including (ii) conjugation events involving sexual pilus or (iii) direct uptake of DNA fragments by transformation or with the help of bacteriophages in 


\section{FIGURE 1 | Continued}

transduction events. The biochemistry of resistance includes (A) altering antibiotic target site, (B) reduced antibiotic uptake, (C) inactivation of antibiotic, and (D) producing alternative targets that are resistant to antibiotics. (B) A model for the trafficking of resistant genes in the human gut. Probiotic bacteria from supplements that harbor resistant determinants (i) can transfer their mobile elements to host gut bacteria (ii). Gut microflora, over time, can build up a reservoir of

antibiotic-resistant genes (iii), which can, in turn, be transferred (iv) to opportunistic pathogens (v) within the gastrointestinal tract, thus rendering antibiotics ineffective (illustration adapted from Zheng et al., 2017). (C) The $\mathrm{pH}$, bile salts, and transit time of food in the gastrointestinal tract. The pH in saliva is between 6.5 and 7.5 . The $\mathrm{pH}$ can reach as low as 1.0 in the stomach, rising to 6.6 in the proximal small intestine and 7.5 in the ileum before falling sharply to 6.4 in the cecum. Bile salts in the gallbladder are approximately $0.7 \%$ (wt/vol), but in the small intestine, it ranges between 0.2 and $2 \%$ (wt/vol) (Kristoffersen et al., 2007). During transit, food is exposed to saliva for up to $1 \mathrm{~min}$ and gastric juice for 1.5 to $4 \mathrm{~h}$. Food transits through the small intestine for approximately 1 to $5 \mathrm{~h}$ and remains in the large intestine for $10 \mathrm{~h}$ to several days.

performed even worse in the presence of bile salts. In particular, the growth of probiotic bacteria dropped 25 and $87.5 \%$ at $\mathrm{pH}$ 3.0 and 1.5, respectively, whereas the presence of bile salts reduced bacteria viability by approximately $50 \%$ at $\mathrm{pH} 7.4$ and 3.0, respectively (Figure $2 \mathrm{~B}$ ). We observed a similar trend in all products tested (data not shown). Therefore, we concluded that probiotics from the examined supplements have poor tolerance to acids and bile salts.

As tolerance to gastrointestinal conditions is crucial for bacteria to be considered as probiotics, many new Lactobacillus isolates from fermented foods and animals have been tested for tolerance to acids and bile salts, and they showed varying degrees of intolerance. For instance, a previous study on Lactobacillus strains isolated from a traditional Iranian cheese showed that only 1 of 28 isolates tolerated acids $(\mathrm{pH} 3.0)$ and bile salts [0.3\% (wt/vol)] (Hassanzadazar et al., 2012). Similarly, 11 Lactobacillus strains obtained from collection centers in Australia also showed varying intolerance to acids and bile salts (Liong and Shah, 2005). It is common for commercial probiotic strains such as Lactobacillus acidophilus NCFM (Wang et al., 2018) and Lactobacillus rhamnosus GG (Corcoran et al., 2005) to be added with sugars or proteins for different buffering capacities, and combined with modern encapsulation technologies (Gbassi and Vandamme, 2012), they can increase the survivability of probiotics transiting in the gastrointestinal tract. Yet, reports of poor tolerance to acids and bile salts of commercial probiotic strains isolated from functional foods (Liong and Shah, 2005; Succi et al., 2005; Sahadeva et al., 2011; Hassanzadazar et al., 2012; Nagyzbekkyzy et al., 2016) suggest that the improvements may be too minimal or transient to be meaningful in vivo. For instance, bacterial strains were considered to be tolerant under short exposures (e.g., 1-2 h) to acids and bile salts (Liong and Shah, 2005; Nagyzbekkyzy et al., 2016), whereas in the gastrointestinal tract, probiotics may be exposed to acidic conditions for approximately 5 to $8 \mathrm{~h}$ (Maurer et al., 2015). As such, it remains uncertain if and to what degree probiotics from supplements can confer the claimed health benefits.

\section{ANTIBIOTIC RESISTANCE IN PROBIOTICS FROM HEALTH SUPPLEMENTS}

Arguably the biggest health concern of consuming probiotic supplements is the risk of transferring resistant determinants. Here, we screened the probiotic supplements for susceptibility to more than 30 types of antibiotics representing different modes of actions (Figure 2C). We employed the disc diffusion method for this study using commercially available antibiotic discs (HiMedia, India). We spread probiotics dissolved in PBS onto MRS agar plates to create an even lawn of bacteria and incubate at similar conditions. Inhibition (clear) zones forming around the antibiotic discs would indicate failure of bacteria to grow around that particular antibiotic, and those with diameters of less than $12 \mathrm{~mm}$, that is, twice the diameter of the disc, are considered "resistant." We presented our data as a heat map in Figure 2C, where green represents susceptible and red represents resistant to the antibiotic. Based on Figure 2C, product B is resistant to six antibiotics, namely, teicoplanin, vancomycin, amikacin, tobramycin, ciprofloxacin, and sparfloxacin, which have different modes of actions, for example, inhibiting cell wall, protein, or DNA synthesis. Interestingly, there were no probiotics resistant to antibiotics that act on ribosome $50 \mathrm{~S}$.

Previous studies have shown that antibiotic-resistant genes can be transferred from one probiotic to another and from probiotics to pathogens in vitro (Tannock et al., 1994). Crucially, in the gut of mice, high transfer frequencies of vancomycinresistant gene from Enterococcus to L. acidophilus were detected (Mater et al., 2008). Also in mice, a recent report has detected the coexistence of $\operatorname{erm}(B)$ as well as tet genes and transposons on single plasmids of three Lactobacillus strains. The authors demonstrated the transfer of these resistant genes to pathogens in mice upon successful colonization of the gut (Thumu and Halami, 2019). These reports are not surprising, given that relatively stable conditions in the gut, such as temperature, nutrients, and food debris, as well as the presence of a rich microflora, favor horizontal gene transfers (Lerner et al., 2017). In the event of an infection, pathogens that have acquired resistant genes may become resistant to and eventually exhaust the options of antibiotics. Because of the high amounts of probiotics consumed through probiotic supplements and their increasing popularity, the clinical ramifications and the longterm implications to human health have become more significant (Zheng et al., 2017; Kothari et al., 2019).

In addition to evidence from mice models, native human gut bacteria have also been shown to harbor various antibioticresistant genes. One study that compared the resistome of Bifidobacterium in newborn infants and in older children or adults showed that antibiotic-resistant genes are not only prevalent in gut Bifidobacterium, but they also built up a more robust arsenal of antibiotic-resistant genes in older children and adults (Duranti et al., 2017). Current technologies 
A
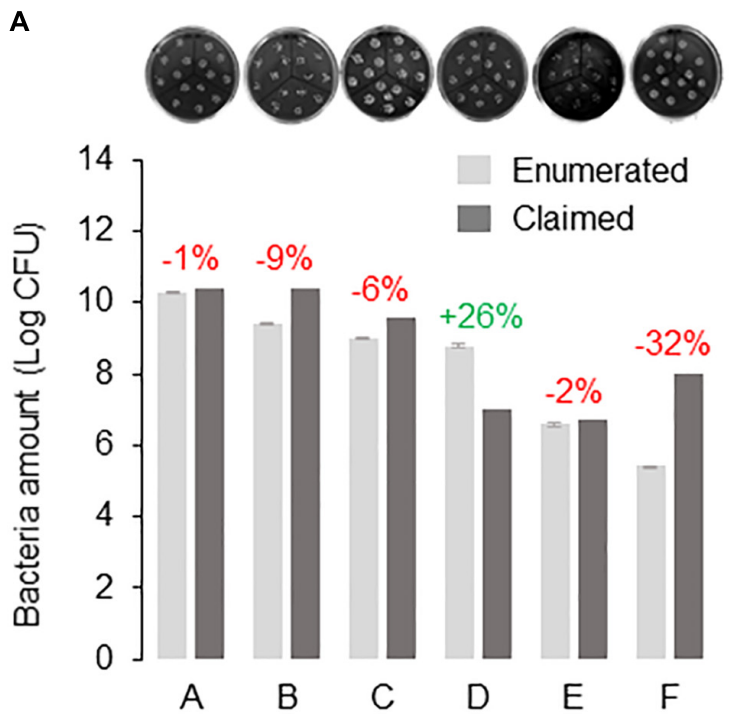
$A, B$ and $C=$ amount per capsule
D = amount per gram
$\mathrm{E} \quad=$ amount per tablet
$\mathrm{F} \quad=$ amount per 5 drops
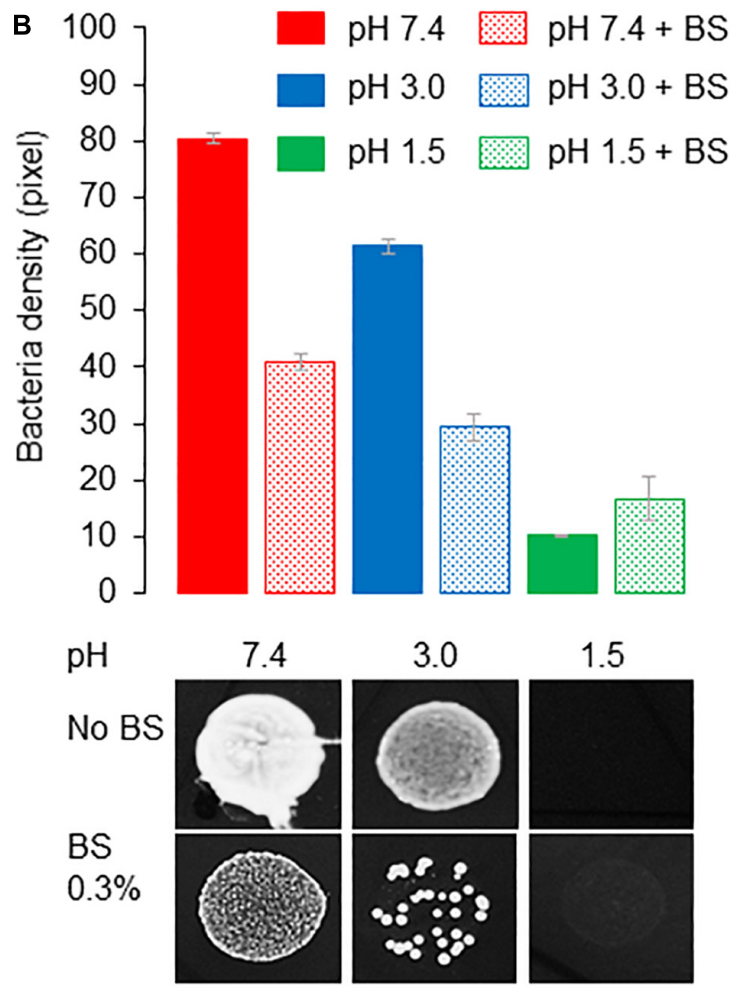

C Mode of action Antibiotics

Cellnall

Cefuroxine

Ampicilincloxecin

Anpcilinclo

Celoperazone

Augnertin/Anoxydav

Ceírisone

Anoxgalin

Fenialing

Oxaciln

Cetalexin

Cekscoln

Vanoomsoin

Ribosome 30 A Aniksin

Gentsniain

Tobramain

Srepmomain

Tetragdine

Ribosome 50S $\begin{aligned} & \text { Tetagoine } \\ & \text { feithromain } \\ & \text { Raxtromyain }\end{aligned}$

Crsithongan

Eseremsoin

Cindantyan

Lnoomyain

Lnezold

Chlorampheniod

Cipotoracin

Soarfoxain

Ofoxacin

co-Trinoxazde

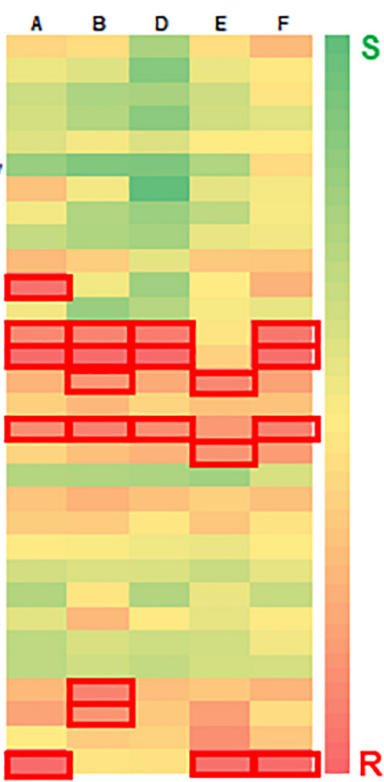

Susceptible

$\square=$ Resistant

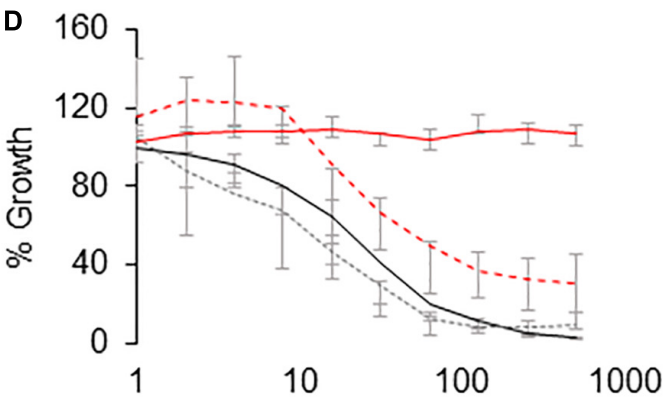

Streptomycin $(\mu \mathrm{g} / \mathrm{mL})$

Cycle 1

Cycle 2

Cycle 3

Cycle 4

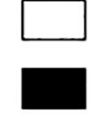

No antibiotic

$512 \mu \mathrm{g} / \mathrm{mL}$

Streptomycin

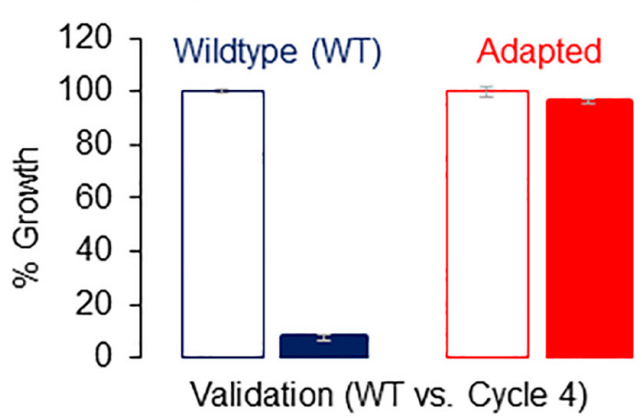

FIGURE 2 | Tolerance of probiotics from supplements to gut conditions and antibiotics. (A) Bacteria enumeration reveals amounts comparable to that claimed by the manufacturers except for product $F$. Enumerated amounts were expressed as percentage of that claimed by manufacturers, where red indicates fewer and green indicates higher than claimed. Probiotic bacteria cultured on MRS agar using the drop plate method were incubated overnight at $37^{\circ} \mathrm{C}$, and the number of bacteria colonies was estimated using ImageJ (Schneider et al., 2012) from high-resolution images. Representative images of bacteria recovered from the probiotic supplements are shown in the top panel. (B) Probiotics from product B showed poor tolerance to acidic pH and bile salts. Probiotics were dissolved in PBS adjusted to the respective $\mathrm{pHs}$ with or without $0.3 \%$ (wt/vol) bile salts before dropping onto MRS agar plate and incubated at similar conditions. Bacteria amounts were (Continued) 


\section{FIGURE 2 | Continued}

estimated by measuring the density of bacteria (by pixel) using ImageJ (Schneider et al., 2012) from high-resolution photos. Bacteria growth at pH 7.4 with no bile salts was used as control. Growth of probiotic bacteria from product B dropped 25 and $87.5 \%$ at $\mathrm{pH} 3.0$ and 1.5 , respectively, whereas the presence of bile salts reduced bacteria viability by approximately $50 \%$ at $\mathrm{pH} 7.4$ and 3.0 respectively. Representative images of bacteria spots from product $\mathrm{B}$ in the respective treatments are shown in the bottom panel. (C) A heat map of antibiotic-resistant profiles of probiotics. Probiotics dissolved in PBS were spread onto MRS agar, and antibiotic susceptibility tests were performed using commercially available antibiotic discs (HiMedia; India). Inhibition zones with diameter larger than 12 mm (i.e., twice the diameter of the disc) were considered "resistant" (boxed in red). All experiments were performed in triplicates, and error bars indicate standard error of the mean. (D) Probiotic bacteria from product B can adapt to high dosage of streptomycin in vitro. Probiotics were cultured in MRS broth containing a gradient of streptomycin $(0-512 \mu \mathrm{g} / \mathrm{mL}$ ), and bacteria growth was estimated by reading the absorbance at $600 \mathrm{~nm}$ (cycle 1). Wells containing bacteria of at least $80 \%$ of the no-antibiotic control were selected for the subsequent cycle(s) of adaptive evolution until $512 \mu \mathrm{g} / \mathrm{mL}$ of streptomycin or the highest possible concentration of streptomycin where $80 \%$ growth can be achieved (Jahn et al., 2017). Probiotics from product B were able to achieve near $100 \% \mathrm{growth}$ at $512 \mu \mathrm{g} / \mathrm{mL}$ of streptomycin after four cycles of adaptive evolution.

employing metagenomics approaches have enabled the diversity and dynamics of antibiotic-resistant genes in the gut microbiota to be studied and compared across populations (van Schaik, 2015). For instance, a study of 162 individuals has identified 1,093 antibiotic-resistant genes, of which Chinese individuals harbor the highest amount of antibiotic-resistant genes, followed by Danish and Spanish individuals (Hu et al., 2014).

In 2016, Imperial and Ibana described the effects of probiotics as a "double-edged" sword that is skewed toward the benefits in, for example, human health and agriculture, while underestimating the risk associated with trafficking antibioticresistant determinants. Given the lack of regulations for probiotic use especially in human health and agriculture activities, they advocated for the screening of probiotics used in livestock and human applications to reduce the spread of antibiotic-resistant genes (Imperial and Ibana, 2016) since they have already been detected in probiotic strains from foods. For instance, genes conferring resistance to tetracycline, erythromycin, aminoglycoside, $\beta$-lactam, macrolide, and chloramphenicol have been found in Lactobacillus, Bifidobacterium, and/or Bacillus probiotic strains (Gueimonde et al., 2013). Commercial probiotic strains, mostly Lactobacillus and Bifidobacterium, which are resistant to antibiotics and their corresponding resistant determinants have been reported in fermented sausages and vegetables, cheese, milk culture, yogurts, and drink beverages (Sharma et al., 2014). Notably, in only one known previous screening attempt on probiotics from supplements, resistance to streptomycin, vancomycin, and ciprofloxacin was reported. No resistance to erythromycin, clindamycin, tetracycline, and ampicillin was detected, and this is consistent with the results in this study. However, resistance to cephalexin, which was not found in the previous study, was detected here (Wong et al., 2015). It is increasingly clear that antibiotic-resistant genes are ubiquitously present in probiotics across all food categories and in the human microbiota. Interestingly, a correlation between the abundance of antibiotic-resistant genes in animal and in human guts has been demonstrated (Rolain, 2013; Hu et al., 2014). These reports have shown that foods, especially those treated with antibiotics and/or in which antibiotic-resistant genes were deliberately added, can establish a reservoir of antibiotic-resistant genes in the microbiota of the human gut (Gueimonde et al., 2013; Penders et al., 2013; Rolain, 2013; Hu et al., 2014; Sharma et al., 2014; van Schaik, 2015; Wong et al., 2015; Imperial and Ibana, 2016; Duranti et al., 2017; Zheng et al., 2017; Lerner et al., 2019).

Next, we investigate if probiotic bacteria from supplements can acquire resistance to a particular antibiotic using an adaptive evolution approach detailed in Jahn et al. (2017). Because product $\mathrm{B}$ contained probiotics displaying resistance to most antibiotics, it was selected for this adaptive evolution study. Importantly, product B did not show resistance to streptomycin, which was the antibiotic selected for this study. Briefly, we treated the probiotic bacteria grown in MRS broth on 96well plates, to a gradient of streptomycin $(0-512 \mu \mathrm{g} / \mathrm{mL})$, and read the absorbance at $600 \mathrm{~nm}$, which correlates with their growth. We considered this as one progressive evolution cycle (cycle 1). Those showing growth of at least $80 \%$ of that in the no-antibiotic wells were selected for the next cycle (cycle 2) of antibiotic gradient treatment. We demonstrate that probiotics from product $\mathrm{B}$ have adapted to streptomycin (512 $\mu \mathrm{g} / \mathrm{mL}$ ) after only four cycles of laboratory adaptive evolution (Figure 2D). We also validated the adapted bacteria comparing their tolerance to $512 \mu \mathrm{g} / \mathrm{mL}$ of streptomycin to that of the wild type and observed that the adapted probiotic bacteria but not the non-adapted bacteria from product B could reach near $100 \%$ growth at $512 \mu \mathrm{g} / \mathrm{mL}$ of streptomycin (Figure 2D). This proof-of-concept study highlights the remarkable ability of probiotics from supplements to adapt quickly and gain resistance to antibiotics.

\section{DISCUSSION}

Following this study, adaptation of probiotics from supplements to other classes of antibiotics should be attempted using similar approaches. We speculate that under antibiotic pressure probiotics may reduce growth and divert resources for survivability. Therefore, probiotics may fail to "climb" the antibiotic gradient or grow much slower at higher doses even after several cycles of adaptive evolution. If this is true, it is conceivable that probiotic bacteria can still shuttle resistant determinants in the gut. Comparative genomics approach, for example, metagenomics sequencing or similar genome-level assessments advocated by others, will be able to reveal the functional gene groups and metabolic pathways of antibiotic-treated probiotics (Zheng et al., 2017; Das et al., 2020; Evanovich et al., 2019; Fontana et al., 2019). To circumvent this problem, 
resistant determinants from probiotic strains such as those from Lactobacillus reuteri (ATCC 55730) (Rosander et al., 2008) could be removed prior to commercial applications in therapeutics and foods.

Besides the risk of trafficking antibiotic-resistant genes, probiotics may even be detrimental to at-risk groups such as newborns and those with weakened immunity. In vulnerable individuals, including persons with diabetes, those with cancer, and organ transplant patients, probiotics may cause localized and/or systemic infections that could lead to organ failure upon penetrating the intestinal mucosa and into the bloodstream (Kothari et al., 2019). Localized effects of probiotics include metabolic disturbances leading to opportunistic infections caused by bacteriophages virulence factors and metabolites of probiotics, as well as establishment of probiotic mobilome, gas, and bloating of the intestine as a result of intestinal probiotic overgrowth (Zmora et al., 2018; Lerner et al., 2019). Systemic effects of probiotics may include autoimmune diseases resulting from probiotics-triggered cytokine production, D-lactic acidosis, and brain fogginess (Kothari et al., 2019; Lerner et al., 2019). In light of these adverse effects, labels on probiotic supplements should contain results of clinical studies and warnings for atrisk groups, while governing bodies such as the Food and Drug Administration should check for misconducts including overestimation of bacteria, misidentification of probiotic strains, and unsupported health claims on product labels because these are common issues in food supplements (Berner and O'Donnell, 1998; Hamilton-Miller et al., 1999).

\section{CONCLUSION}

In conclusion, we have highlighted the intolerance of probiotics from supplements to acids and bile salts in addition to their resistance (and adaptation) to antibiotic(s). In an environment where consuming supplements is considered a norm, our results and that of others will put in perspective the persisting concerns

\section{REFERENCES}

Balcazar, J. L. (2014). Bacteriophages as vehicles for antibiotic resistance genes in the environment. PLoS Pathog. 10:e1004219. doi: 10.1371/journal.ppat.100 4219

Bennett, P. M. (2008). Plasmid encoded antibiotic resistance: acquisition and transfer of antibiotic resistance genes in bacteria. Br. J. Pharmacol. 153(Suppl 1), S347-S357. doi: 10.1038/sj.bjp.0707607

Berner, L. A., and O'Donnell, J. A. (1998). Functional foods and health claims legislation: applications to dairy foods. Int. Dairy J. 8, 355-362. doi: 10.1016/ s0958-6946(98)00058-2

Bielecki, P., Lukat, P., Hüsecken, K., Dötsch, A., Steinmetz, H., Hartmann, R. W., et al. (2012). Mutation in elongation factor $G$ confers resistance to the antibiotic argyrin in the opportunistic pathogen Pseudomonas aeruginosa. Chembiochem 13, 2339-2345. doi: 10.1002/cbic.201200479

Blair, J. M., Webber, M. A., Baylay, A. J., Ogbolu, D. O., and Piddock, L. J. (2014). Molecular mechanisms of antibiotic resistance. Nat. Rev. Microbiol. 13, 42-51.

Broaders, E., Gahan, C. G., and Marchesi, J. R. (2013). Mobile genetic elements of the human gastrointestinal tract: potential for spread of antibiotic resistance genes. Gut Microbes 4, 271-280. doi: 10.4161/gmic.24627

Colavecchio, A., Cadieux, B., Lo, A., and Goodridge, L. D. (2017). Bacteriophages contribute to the spread of antibiotic resistance genes among foodborne surrounding probiotic supplements so that the current hype does not overpower the hope.

\section{DATA AVAILABILITY STATEMENT}

The datasets generated for this study are available on request to the corresponding author.

\section{AUTHOR CONTRIBUTIONS}

AW conceived this project, wrote the manuscript and made the figures, and acquired the funding. AW, XW, XC, and CS performed the bacterial enumeration. AW, MZ, RZ, HY, and HA performed the antibiotic susceptibility test. AW, YaW, YJ, YuW, MD, JL, XJ, LS, and YH performed the adaptive evolution study. AW, YuW, YJ, YD, and CY analyzed the data and made the figures. AW, HY, and HA supervised and managed the project. All authors prepared, read and approved the final version of the manuscript.

\section{FUNDING}

This research received funding from the Office of Research and Sponsored Programs of Wenzhou-Kean University under the Students Partnering with Faculty $(\mathrm{SpF})$ research program (Grant no. WKU201617002, WKU201718009, WKU201819002, and WKU20192009) awarded to AW.

\section{SUPPLEMENTARY MATERIAL}

The Supplementary Material for this article can be found online at: https://www.frontiersin.org/articles/10.3389/fmicb. 2020.00160/full\#supplementary-material

pathogens of the Enterobacteriaceae family - a review. Front. Microbiol. 8:1108. doi: $10.3389 /$ fmicb. 2017.01108

Corcoran, B. M., Stanton, C., Fitzgerald, G. F., and Ross, R. P. (2005). Survival of probiotic lactobacilli in acidic environments is enhanced in the presence of metabolizable sugars. Appl. Environ. Microbiol. 71, 3060-3067. doi: 10.1128/ AEM.71.6.3060-3067.2005

Das, D. J., Shankar, A., Johnson, J. B., and Thomas, S. (2020). Critical insights into antibiotic resistance transferability in probiotic Lactobacillus. Nutrition 69:110567. doi: 10.1016/j.nut.2019.110567

Du Toit, A. (2018). Antimicrobials: bacterial enzymes 'straighten out' antibiotics. Nat. Rev. Microbiol. 16:122. doi: 10.1038/nrmicro. 2018.19

Duranti, S., Lugli, G. A., Mancabelli, L., Turroni, F., Milani, C., Mangifesta, M., et al. (2017). Prevalence of antibiotic resistance genes among human gutderived bifidobacteria. Appl. Environ. Microbiol. 83:e2894-16. doi: 10.1128/ AEM.02894-16

Evanovich, E., de Souza Mendonça Mattos, P. J., and Guerreiro, J. F. (2019). Comparative genomic analysis of Lactobacillus plantarum: an overview. Int. J. Genomics 2019:4973214. doi: 10.1155/2019/4973214

Evans, D. F., Pye, G., Bramley, R., Clark, A. G., Dyson, T. J., and Hardcastle, J. D. (1988). Measurement of gastrointestinal $\mathrm{pH}$ profiles in normal ambulant human subjects. Gut 29, 1035-1041. doi: 10.1136/gut.29.8.1035 
Fajardo, A., and Martínez, J. L. (2008). Antibiotics as signals that trigger specific bacterial responses. Curr. Opin. Microbiol. 11, 161-167. doi: 10.1016/j.mib.2008. 02.006

Fontana, A., Falasconi, I., Molinari, P., Treu, L., Basile, A., Vezzi, A., et al. (2019). Genomic comparison of Lactobacillus helveticus strains highlights probiotic potential. Front. Microbiol. 10:1380. doi: 10.3389/fmicb.2019. 01380

Gbassi, G. K., and Vandamme, T. (2012). Probiotic encapsulation technology: from microencapsulation to release into the gut. Pharmaceutics 4, 149-163. doi: 10.3390/pharmaceutics4010149

Gueimonde, M., Sánchez, B., de los Reyes-Gavilán, C., and Margolles, A. (2013). Antibiotic resistance in probiotic bacteria. Front. Microbiol. 4:202. doi: 10.3389/ fmicb.2013.00202

Gutierrez, A., Laureti, L., Crussard, S., Abida, H., Rodríguez-Rojas, A., Blázquez, J., et al. (2013). $\beta$-lactam antibiotics promote bacterial mutagenesis via an RpoSmediated reduction in replication fidelity. Nat. Commun. 4:1610. doi: 10.1038/ ncomms 2607

Haas, D., and Défago, G. (2005). Biological control of soil-borne pathogens by fluorescent pseudomonads. Nat. Rev. Microbiol. 3, 307-319. doi: 10.1038/ nrmicro1129

Hamilton-Miller, J. M. T., Shah, S., and Winkler, J. T. (1999). Public health issues arising from microbiological and labelling quality of foods and supplements containing probiotic microorganisms. Public Health Nutr. 2, 223-229. doi: $10.1017 / \mathrm{s} 1368980099000282$

Hassanzadazar, H., Ehsani, A., Mardani, K., and Hesari, J. (2012). Investigation of antibacterial, acid and bile tolerance properties of lactobacilli isolated from Koozeh cheese. Vet. Res. Forum 3, 181-185.

Hawkey, P. M. (1998). The origins and molecular basis of antibiotic resistance. BMJ 317, 657-660. doi: 10.1136/bmj.317.7159.657

Hirayama, K., and Rafter, J. (2000). The role of probiotic bacteria in cancer prevention. Microbes Infect. 2, 681-686. doi: 10.1016/s1286-4579(00)00 357-9

Homayouni, A., Alizadeh, M., Alikhah, H., and Zijah, V. (2012). "Functional dairy probiotic food development: trends, concepts, and products," in Immunology and Microbiology: "Probiotics", ed. E. Rigobelo (Rijeka: InTech), 197-212. doi: $10.5772 / 48797$

Hu, Y., Yang, X., Lu, N., and Zhu, B. (2014). The abundance of antibiotic resistance genes in human guts has correlation to the consumption of antibiotics in animal. Gut microbes 5, 245-249. doi: 10.4161/gmic. 27916

Imperial, I. C., and Ibana, J. A. (2016). Addressing the antibiotic resistance problem with probiotics: reducing the risk of its double-edged sword effect. Front. Microbiol. 7:1983. doi: 10.3389/fmicb.2016.01983

Jahn, L. J., Munck, C., Ellabaan, M. M. H., and Sommer, M. O. A. (2017). Adaptive laboratory evolution of antibiotic resistance using different selection regimes lead to similar phenotypes and genotypes. Front. Microbiol. 8:816. doi: 10.3389/ fmicb.2017.00816

Jiang, X., Ellabaan, M. M. H., Charusanti, P., Munck, C., Blin, K., Tong, Y., et al. (2017). Dissemination of antibiotic resistance genes from antibiotic producers to pathogens. Nat. Commun. 8:15784. doi: 10.1038/ncomms15784

Kaur, I. P., Chopra, K., and Saini, A. (2002). Probiotics: potential pharmaceutical applications. Eur. J. Pharm. Sci. 15, 1-9. doi: 10.1016/s0928-0987(01)00209-3

Kechagia, M., Basoulis, D., Konstantopoulou, S., Dimitriadi, D., Gyftopoulou, K., Skarmoutsou, N., et al. (2013). Health benefits of probiotics: a review. ISRN Nutri. 2013:481651. doi: 10.5402/2013/481651

Kohanski, M. A., Dwyer, D. J., and Collins, J. J. (2010). How antibiotics kill bacteria: from targets to networks. Nat. Rev. Microbiol. 8, 423-435. doi: 10.1038/ nrmicro2333

Kothari, D., Patel, S., and Kim, S. K. (2019). Probiotic supplements might not be universally-effective and safe: a review. Biomed. Pharmacother. 111, 537-547. doi: 10.1016/j.biopha.2018.12.104

Kristoffersen, S. M., Ravnum, S., Tourasse, N. J., Økstad, O. A., Kolstø, A. B., and Davies, W. (2007). Low concentrations of bile salts induce stress responses and reduce motility in Bacillus cereus ATCC 14579. J. Bacteriol. 189, 5302-5313. doi: 10.1128/jb.00239-07

Lerner, A., Matthias, T., and Aminov, R. (2017). Potential effects of horizontal gene exchange in the human gut. Front. Immunol. 8:1630. doi: 10.3389/fimmu.2017. 01630
Lerner, A., Shoenfeld, Y., and Matthias, T. (2019). Probiotics: if it does not help it does not do any harm. Really? Microorganisms 7:104. doi: 10.3390/ microorganisms7040104

Lin, J., Nishino, K., Roberts, M. C., Tolmasky, M., Aminov, R. I., and Zhang, L. (2015). Mechanisms of antibiotic resistance. Front. Microbiol. 6:34. doi: 10. 3389/fmicb.2015.00034

Liong, M. T., and Shah, N. P. (2005). Acid and bile tolerance and cholesterol removal ability of Lactobacilli strains. J. Dairy Sci. 88, 55-66. doi: 10.3168/jds. s0022-0302(05)72662-x

Martinez, J. L., Fajardo, A., Garmendia, L., Hernandez, A., Linares, J. F., MartinezSolano, L., et al. (2009). A global view of antibiotic resistance. FEMS Microbiol. Rev. 33, 44-65. doi: 10.1111/j.1574-6976.2008.00142.x

Mater, D. D., Langella, P., Corthier, G., and Flores, M. J. (2008). A probiotic Lactobacillus strain can acquire vancomycin resistance during digestive transit in mice. J. Mol. Microb. Biotech. 14, 123-127. doi: 10.1159/000106091

Maurer, J. M., Schellekens, R. C., van Rieke, H. M., Wanke, C., Iordanov, V., Stellaard, F., et al. (2015). Gastrointestinal pH and transit time profiling in healthy volunteers using the IntelliCap system confirms ileo-colonic release of ColoPulse tablets. PLoS One 10:e0129076. doi: 10.1371/journal.pone.0129076

Nagpal, R., Kumar, A., Kumar, M., Behare, P. V., Jain, S., and Yadav, H. (2012). Probiotics, their health benefits and applications for developing healthier foods: a review. FEMS Microbiol. Lett. 334, 1-15. doi: 10.1111/j.15746968.2012.02593.x

Nagyzbekkyzy, E., Abitayeva, G., Anuarbekova, S., Shaikhina, D., Li, K., Shaikhin, S., et al. (2016). Investigation of acid and bile tolerance, antimicrobial activity and antibiotic resistance of Lactobacillus strains Isolated from Kazakh dairy foods. Asian J. Appl. Sci. 9, 143-158. doi: 10.3923/ajaps.2016.143.158

O'Connell, D. P. (2001). Mechanisms of antibiotic action and resistance. Trends Microbiol. 9:410. doi: 10.1016/s0966-842x(01)02179-5

Penders, J., Stobberingh, E., Savelkoul, P., and Wolffs, P. (2013). The human microbiome as a reservoir of antimicrobial resistance. Front. Microbiol. 4:87. doi: $10.3389 /$ fmicb.2013.00087

Perdigon, G., Fuller, R., and Raya, R. (2001). Lactic acid bacteria and their effect on the immune system. Curr. Issues Intest. Microbiol. 2, 27-42.

Rolain, J. M. (2013). Food and human gut as reservoirs of transferable antibiotic resistance encoding genes. Front. Microbiol. 4:173. doi: 10.3389/fmicb.2013. 00173

Romero, D., Traxler, M. F., López, D., and Kolter, R. (2011). Antibiotics as signal molecules. Chem. Rev. 111, 5492-5505. doi: 10.1021/cr2000509

Rosander, A., Connolly, E., and Roos, S. (2008). Removal of antibiotic resistance gene-carrying plasmids from Lactobacillus reuteri ATCC 55730 and characterization of the resulting daughter strain, L. reuteri DSM 17938. Appl. Environ. Microbiol. 74, 6032-6040. doi: 10.1128/AEM.00991-08

Sahadeva, R. P. K., Leong, S. F., Chua, K. H., Tan, C. H., Chan, H. Y., Tong, E. V., et al. (2011). Survival of commercial probiotic strains to $\mathrm{pH}$ and bile. Int. Food Res. J. 18, 1515-1522.

Schneider, C. A., Rasband, W. S., and Eliceiri, K. W. (2012). NIH Image to ImageJ: 25 years of image analysis. Nat. Meth. 9, 671-675. doi: 10.1038/nmeth.2089

Shah, N. P. (2000). Probiotic bacteria: selective enumeration and survival in dairy foods. J. Dairy Sci. 83, 894-907. doi: 10.3168/jds.s0022-0302(00)74953-8

Sharma, P., Tomar, S. K., Goswami, P., Sangwan, V., and Singh, R. (2014). Antibiotic resistance among commercially available probiotics. Food Res. Int. 57, 176-195. doi: 10.1016/j.foodres.2014.01.025

Stokes, H. W., and Gillings, M. R. (2011). Gene flow, mobile genetic elements and the recruitment of antibiotic resistance genes into gram-negative pathogens. FEMS Microbiol. Rev. 35, 790-819. doi: 10.1111/j.1574-6976.2011.00273.x

Succi, M., Tremonte, P., Reale, A., Sorrentino, E., Grazia, L., Pacifico, S., et al. (2005). Bile salt and acid tolerance of Lactobacillus rhamnosus strains isolated from Parmigiano Reggiano cheese. FEMS Microbiol. Lett. 244, 129-137. doi: 10.1016/j.femsle.2005.01.037

Tannock, G. W., Luchansky, J. B., Miller, L., Connell, H., Thode-Andersen, S., Mercer, A. A., et al. (1994). Molecular characterization of a plasmid-borne (pGT633) erythromycin resistance determinant (ermGT) from Lactobacillus reuteri 100-63. Plasmid 31, 60-71. doi: 10.1006/plas.1994.1007

Thumu, S. C. R., and Halami, P. M. (2019). Conjugal transfer of erm(B) and multiple tet genes from Lactobacillus spp. to bacterial pathogens in animal gut, in vitro and during food fermentation. Food Res. Int. 116, 1066-1075. doi: 10.1016/j.foodres.2018.09.046 
van Schaik, W. (2015). The human gut resistome. Philos. Trans. R. Soc. Lond. B Biol. Sci. 370:20140087. doi: 10.1098/rstb.2014. 0087

Wang, R. M., Li, N., Zheng, K., and Hao, J. F. (2018). Enhancing acid tolerance of the probiotic bacterium Lactobacillus acidophilus NCFM with trehalose. FEMS Microbiol. Lett. 365:fny217. doi: 10.1093/femsec/fny217

Wong, A., Ngu, D. Y., Dan, L. A., Ooi, A., and Lim, R. L. (2015). Detection of antibiotic resistance in probiotics of dietary supplements. Nutr. J. 14:95. doi: 10.1186/s12937-015-0084-2

Woodford, N., and Ellington, M. J. (2007). The emergence of antibiotic resistance by mutation. Clin. Microbiol. Infect. 13, 5-18. doi: 10.1111/j.1469-0691.2006. 01492.x

Yim, G., de la Cruz, F., Spiegelman, G. B., and Davies, J. (2006). Transcription modulation of Salmonella enterica serovar Typhimurium promoters by subMIC levels of rifampin. J. Bacteriol. 188, 7988-7991. doi: 10.1128/jb.00 791-06

Yim, G., Wang, H. H., and Davies, J. (2007). Antibiotics as signalling molecules. Philos. Trans. R. Soc. Lond. B Biol. Sci. 362, 1195-1200. doi: 10.1098/rstb.2007. 2044
Zheng, M., Zhang, R., Tian, X., Zhou, X., Pan, X., and Wong, A. (2017). Assessing the risk of probiotic dietary supplements in the context of antibiotic resistance. Front. Microbiol. 8:908. doi: 10.3389/fmicb.2017.00908

Zmora, N., Zilberman-Schapira, G., Suez, J., Mor, U., Dori-Bachash, M., Bashiardes, S., et al. (2018). Personalized gut mucosal colonization resistance to empiric probiotics is associated with unique host and microbiome features. Cell 174, 1388-1405. doi: 10.1016/j.cell.2018.08.041

Conflict of Interest: The authors declare that the research was conducted in the absence of any commercial or financial relationships that could be construed as a potential conflict of interest.

Copyright (c) 2020 Wang, Jiang, Deng, Yi, Wang, Ding, Liu, Jin, Shen, He, Wu, Chen, Sun, Zheng, Zhang, Ye, An and Wong. This is an open-access article distributed under the terms of the Creative Commons Attribution License (CC BY). The use, distribution or reproduction in other forums is permitted, provided the original author(s) and the copyright owner(s) are credited and that the original publication in this journal is cited, in accordance with accepted academic practice. No use, distribution or reproduction is permitted which does not comply with these terms. 